\title{
Palliative care: the need of the modern era
}

\author{
KS Chan *
}

\section{A B S T R A C T}

There is a great need for palliative care in the modern era of medicine. Despite medical advances, patients with life-limiting illnesses still suffer significantly. Palliative care emerged a half century ago as an ethos based on compassion and care for patients and their families to relieve their suffering. It entails a paradigm shift from the biomedical model to the biopsychospiritual model. Palliative care is recognised by the World Health Organization as an essential part of the continuum of universal health coverage. In 2014, the World Health Assembly approved a resolution on "Strengthening of palliative care as a component of comprehensive care throughout the life course". Despite Hong Kong's relatively good local palliative care service coverage for patients who died of cancer and endstage renal failure, service gaps for palliative care do exist among our ageing population with non-

This article was published on $30 \mathrm{Jul}$ 2018 at www.hkmj.org. malignant life-limiting illnesses. We strongly urge the Hong Kong Government to develop our local palliative care policy in response to the World Health Assembly's resolution. Growing international and local evidence demonstrates the impacts of palliative care on patient outcomes, caregivers, and health care. Such outcomes can be service-based, diseasebased, or symptom/suffering-based. The goal of palliative care is to relieve health-related suffering. Evidence-based management of pain, breathlessness, and psychospiritual suffering are discussed. Care in the end-of-life phase should be an integral part of palliative care, promoting patient choice, advance care planning, and good death.

\section{Hong Kong Med J 2018;24:391-9 DOI: 10.12809/hkmj187310}

KS Chan *, FRCP, FHKAM (Medicine)

Department of Medicine, Haven of Hope Hospital, Tseung Kwan O, Hong Kong

*Corresponding author: chanks@ha.org.hk

\section{The need for palliative care}

Doctors commonly encounter patients who experience distress and suffering. New medical technologies bring new hope for cures but do not always alleviate the distress of patients with lifelimiting illnesses. A systematic review of 38 studies that included 1.2 million older subjects in 10 countries showed that an average of $33 \%$ to $38 \%$ of patients received non-beneficial treatments in the final 6 months of life. ${ }^{1}$ In this unprecedented era of "personalised medicine," health care has become increasingly depersonalised. Nobel Prize laureate Dr Bernard Lown succinctly declared that "Science contributes to abandoning healing". The Cartesian dualism of body and mind has profoundly influenced the development of modern medicine, which is predominantly rooted in the biomedical model. ${ }^{2}$ The modern hospice care movement was advanced a half century ago by Dame Cicely Saunders as an ethos based on compassion and care for patients and their families to relieve their suffering. It entails a paradigm shift from the biomedical model to the biopsychospiritual model, from a diseasecentred approach to person-centred care, and from prolongation of survival to enhancement of the journey's meaningfulness. Palliative care has evolved from hospice care and moved upstream from the end-of-life (EOL) phase to earlier stages of illnesses. ${ }^{3}$ Palliative medicine was established as an independent subspecialty by the Hong Kong College of Physicians and the Hong Kong College of Radiologists in 1998 and 2002, respectively. The year 2017 marked the 35th anniversary of hospice palliative care services in Hong Kong.

The World Health Organization (WHO) defines palliative care as "an approach that improves the quality of life of patients (adults and children) and their families facing the problems associated with life-threatening illness through the prevention and relief of suffering by means of early identification and impeccable assessment and treatment of pain and other problems, physical, psychosocial, or spiritual". Subsequently, its scope was clarified to explain its comprehensiveness, including: (1) no prognostic limitation on palliative care; and (2) the need for palliative care to address both chronic and life-threatening/limiting illness. ${ }^{4,5}$ Palliative care is recognised by the WHO as an essential component of the continuum of universal health coverage, which includes promotion, prevention, cure, rehabilitation, and palliation. ${ }^{5}$ It should be delivered as an integrated approach with concurrent curative or disease-modifying treatment. ${ }^{5}$ Palliative care should be provided at three levels according to patient needs: (1) a "palliative care approach" adopted by all health care professionals; (2) "general palliative 


\section{紓緩治療：現今時代之需要}

陳健生

現代醫學對紓緩治療有極大需要。儘管醫學上取得了先進發展, 但患 有生命限制疾病的病者仍然經常經歷嚴重痛苦。半個世紀前, 紓緩治 療的開展是基於對病人及其家人的憐憫和關懷的精神, 以減輕他們的 痛苦。紓緩治療需要從生物醫學模式轉到身、心、靈模式的範式轉 變。紓緩治療被世界衛生組織（WHO）認可為全民健康覆蓋的連續 體的重要組成部分。2014年, 世界衛生大會通過了一項於「加強紟緩 治療作為在整個生命歷程中整全照顧的一部分」的決議。儘管香港對 於因癌症和末期腎功能衰竭而死亡的患者提供了相對較好的本地紓緩 治療服務, 但在人口老化並患有非惡性生命限制疾病中, 確實存在紓 緩治療的服務缺口。我們強烈要求香港政府根據世界衛生大會的決議 制定本地的紓緩治療政策。越來越多的國際和本地研究表明了紓緩治 療對患者的療效結果, 以及照顧者和醫療制度的影響。這些療效結果 可以是基於服務模式、疾病模式或症狀 / 痛苦模式。紓緩治療的目標 是減輕由身體健康有關的痛苦。本文從實證醫學討論如何處理疼痛 呼吸困難和心理, 以及心靈痛苦。臨終階段的照顧是紓緩治療的一部 分, 目的是促進患者選擇、預設照顧計劃及善終。 care" provided by primary care professionals; and (3) "specialist palliative care" provided by a specialised palliative care team for patients with complex problems. ${ }^{4}$

The WHO estimated that out of 40 million patients at the EOL who need palliative care, only about $14 \%$ currently receive it. ${ }^{4}$ In 2014 , the World Health Assembly (WHA) approved resolution WHA 67.19 on "strengthening of palliative care as a component of comprehensive care throughout the life course". ${ }^{6}$ Its top recommendation for member states is to develop, strengthen, and implement palliative care policies in the continuum of care across all levels, where appropriate. ${ }^{6}$ In 2017, the Hospital Authority released the "Strategic Service Framework for Palliative Care". ${ }^{7}$ Nevertheless, the Hong Kong Government is strongly urged to develop a local palliative care policy in response to the WHA resolution.

In the US, there has been rapid growth of palliative care to improve the quality of dying. In 2000 , only $25 \%$ of US hospitals with more than 50 beds had a palliative care team, whereas in 2015, $75 \%$ of such hospitals offered a palliative care programme. ${ }^{8}$ In Hong Kong, around $68 \%$ of patients who died of cancer under the Hospital Authority in 2012 to 2013 received palliative care. ${ }^{7}$ Since 2010, palliative care has also been systematically extended to patients with advanced non-cancer diseases in Hong Kong. These predominantly include patients with end-stage renal failure, advanced chronic obstructive pulmonary disease (COPD), heart failure, and neurodegenerative conditions such as motor neuron disease. In 2015, a cohort review performed by the Central Committee on Palliative Care of the Hospital Authority indicated that 44\% of patients who died from end-stage renal failure had received palliative care. ${ }^{7}$ However, service gaps for palliative care exist among patients with many non-malignant life-limiting illnesses, especially with the ageing of the local population. ${ }^{7}$ A collaborative approach between palliative care teams and specialist teams is becoming an established model of care for patients entering the palliative care phase of chronic illnesses. $^{7}$

\section{Palliative care improves health outcomes}

There is growing evidence that shows the impacts of palliative care on patient outcomes, caregivers, and health care, which can be service-based, diseasebased, or symptom/suffering-based.

A recent systematic review reported the association between palliative care and the outcomes of patients with life-limiting illness and their caregivers. ${ }^{9}$ A total of 43 investigated randomised controlled trials (RCTs) included 12731 patients and 2479 caregivers. Among these trials, 14 (32.5\%) were in ambulatory settings, 18 (41.8\%) were home-based, and 11 (25.6\%) were hospital-based. A meta-analysis showed that palliative care was associated with statistically and clinically significant improvements in patients' quality of life (QOL) (standardised mean difference $[\mathrm{SMD}]=0.46 ; 95 \%$ confidence intervals $[C I]=0.08-0.83)$ and symptom burden $(S M D=-0.66$; $95 \% \mathrm{CI}=-1.25$ to -0.07$)$ at 1 -to-3-month followup. ${ }^{9}$ There was no association between palliative care and survival (hazard ratio $=0.90 ; 95 \% \mathrm{CI}=0.69$ 1.17). Palliative care was consistently associated with improvements in advance care planning, patient and caregiver satisfaction, and lower health care utilisation. $^{9}$

Early palliative care delivered within 12 weeks of diagnosis of incurable cancers ${ }^{10}$ is a recent service model for patients with advanced cancer. A Cochrane review ${ }^{10}$ on early palliative care for adults with advanced cancer reported on seven RCTs with 1614 participants. Compared with usual/standard cancer care alone, early palliative care significantly improved health-related QOL with a small effect size $(\mathrm{SMD}=0.27 ; 95 \% \mathrm{CI}=0.15-0.38)$, and there was a small but significant effect of lower symptom intensity $(\mathrm{SMD}=-0.23 ; 95 \% \mathrm{CI}=-0.35$ to -0.10$)$. A meta-analysis of four studies did not indicate differences in survival (death hazard ratio $=0.85 ; 95 \%$ $\mathrm{CI}=0.56-1.28) .^{10}$

Home care is an important component of care at advanced stages of illness. A Cochrane review evaluated 23 studies including $16 \mathrm{RCTs}$ on the effectiveness and cost-effectiveness of home palliative care services for adults with advanced illness and their caregivers. ${ }^{11}$ A meta-analysis showed 
that home palliative care increased the odds of dying at home (odds ratio $[\mathrm{OR}]=2.21 ; 95 \% \mathrm{CI}=1.31-3.71$ ). ${ }^{11}$ Narrative synthesis showed evidence of small but statistically significant beneficial effects of home palliative care services compared with usual care: reduction of symptom burden for patients and no effect on caregiver grief. The evidence on costeffectiveness was inconclusive. ${ }^{11}$

A review of the economic impact of in-patient palliative care, which included nine observational studies and one RCT from the US, has also been published. ${ }^{12}$ Each of the studies demonstrated a clear cost-saving impact of in-patient consultation programmes (range of cost savings: 5\%-32\% compared with usual care). ${ }^{12}$

The outcomes of palliative care services in Hong Kong have also been reported. Two instruments assessing the QOL of local Chinese patients at the EOL were validated and applied locally: the McGill Quality of Life Questionnaire-Hong Kong ${ }^{13}$ and the Quality of Life Concerns in the End of Life Questionnaire (QOLC-E). ${ }^{14}$

The impacts of palliative care on cancer deaths in four Hong Kong hospitals have also been reported. ${ }^{15}$ Palliative care was administered in two thirds of 494 cancer deaths, and half died in a palliative care setting. A total of 247 patients received palliative care service and died in palliative care units (PCS-PCD group), 86 received palliative care but died in non-palliative care wards, and 161 never received palliative care and died in non-palliative care wards. During the last 6 months of life, patients in the PCS-PCD group had less admission to acute care wards, shorter duration of stay in acute care wards, and less admission to intensive care units. Within the last 2 weeks of life, the PCS-PCD group had fewer interventions initiated; a higher frequency of symptoms documented in patients' records; and a higher likelihood of receiving analgesics, adjuvant analgesics, and sedatives. ${ }^{15}$

An RCT was conducted in Hong Kong on home-based transitional palliative care for patients with end-stage heart failure after hospital discharge. ${ }^{16}$ The interventions consisted of weekly palliative home visits/telephone calls in the first 4 weeks, then monthly follow-up provided by a nurse case manager supported by a multidisciplinary palliative team. The intervention group $(n=43)$ had a significantly lower readmission rate and mean number of readmissions than the control group $(n=41)$ at 12 weeks. The intervention group experienced significantly greater clinical improvement in depression, dyspnoea, and total Edmonton Symptom Assessment Scale score than the control group did at 4 weeks. ${ }^{16}$

Fewer studies have reported palliative care outcomes in patients with non-cancer illnesses than in those with cancer. A recent review reported positive outcomes of various troublesome symptoms for people with COPD. ${ }^{17}$ A recent meta-analysis of three studies of heart failure patients found that home-based palliative care consultations reduce the risk of re-hospitalisation by $42 \%$ (relative risk $=0.58$; $95 \% \mathrm{Cl}=0.44-0.77){ }^{18}$

A study in Hong Kong explored the symptom burden and QOL of patients with end-stage renal disease who received chronic dialysis or palliative care. ${ }^{19}$ There was significant impairment of QOL in the palliative care and dialysis groups. The authors concluded that patients with end-stage renal disease who received palliative care and dialysis had overlapping symptom prevalence and intensity, significant symptom burden, and impaired QOL. ${ }^{19}$

\section{Relief of suffering as the goal of palliative care}

Pain has been routinely addressed in modern medicine, but suffering has not. The global burden of serious health-related suffering (SHS) from 20 life-threatening diseases was estimated for the first time by the Lancet Commission on Global Access to Palliative Care and Pain Relief. ${ }^{20}$ In 2015, an estimated 25.5 million people died with SHS, and 35.5 million people who did not die also experienced SHS. ${ }^{20}$ The Commission stated that alleviating SHS is imperative for global health and equity and that palliative care should focus on relieving SHS associated with lifelimiting conditions or at the EOL. ${ }^{20}$

"Total pain" was described by Dame Cicely Saunders to illustrate suffering that encompasses all of a person's physical, psychological, social, and spiritual struggles. Closely related to total pain are the concepts of "distress" and "suffering". Suffering was defined by Eric Cassel as "the state of severe distress associated with events that threaten the intactness of person."21 Suffering is personal and individual and can only be communicated by empathetic listening. ${ }^{21}$

All domains of patient suffering, including physical, psychosocial, and spiritual distress, should be assessed and addressed. Communication with the patient is important, especially about pain in relation to disease progression and side-effects of drugs. The National Australian Palliative Care Outcomes Collaboration analysed 19747 patients who showed significant improvements of palliative care outcomes across all domains of symptom control, family care, and psychological and spiritual care, except pain. ${ }^{22}$ Pain, breathlessness, and depression are prevalent and distressing EOL experiences for patients and families and will be reviewed below.

\section{Evidence-based pain management}

The second edition of the WHO Guideline on Cancer Pain Relief, issued in 1996, remains the most widely used pain guideline based on expert opinion instead of evidence-based review. Its purpose is to 
facilitate and legitimise the use of "strong" opioids in regions where these medications are illegal. The greatest barrier against pain control worldwide is opioid availability. ${ }^{20}$

Cancer pain guidelines based on evidence have been published. ${ }^{23,24}$ Despite the wide use of paracetamol for cancer pain, the evidence supporting its use in combination with step $\mathrm{III}^{25}$ or step II/III ${ }^{26}$ opioids is weak. A Cochrane review on non-steroidal anti-inflammatory drugs in 2017 concluded there is no high-quality evidence to support or refute the use of non-steroidal anti-inflammatory drugs alone or in combination with opioids in the WHO analgesic ladder's three steps. ${ }^{27}$ There is low-quality evidence that some people (26\% and $51 \%$ ) with moderate or severe cancer pain can obtain substantial benefits within 1 or 2 weeks. ${ }^{27}$

There is evidence supporting the use of codeine ${ }^{28}$ but there is only weak evidence supporting the use of tramadol for cancer pain. A Cochrane review on tramadol with or without paracetamol for cancer pain in $2017^{29}$ mentioned limited, low-quality evidence from RCTs that tramadol relieved cancer pain. The authors concluded that its role in step II of the WHO analgesic ladder is unclear. ${ }^{29}$ Some national cancer pain guidelines prefer the use of codeine over tramadol as a choice of weak opioids. ${ }^{23}$

A systematic review by Caraceni et $\mathrm{al}^{30}$ suggested that oral morphine, hydromorphone, oxycodone, and methadone offer similar pain relief with similar patterns of side-effects. The choice among these drugs can be influenced by availability, cost, and other local considerations. ${ }^{30}$ Transdermal fentanyl may be associated with less constipation and good patient compliance but may not be a first choice in opioid-naïve patients. ${ }^{30}$ A 2017 Cochrane systemic review on oxycodone confirmed that oxycodone offers similar levels of pain relief and overall adverse events to other opioids, including morphine. ${ }^{31}$

The analgesic effects of opioids are affected by genetic variation: for example, variations in $\mu$-opioid receptor gene OPRM1, catechol-O-methyltransferase, and opioid transporter $\mathrm{ABCB} 1$ are associated with variation of analgesic response to morphine, and genetic variation of CYP2D6 is associated with different responses to codeine and tramadol. ${ }^{32}$ In the future, pharmacogenomics will guide personalised medicine selection in pain control.

Based on Bennett's review, ${ }^{33}$ amitriptyline and gabapentin are recommended by the European Association for Palliative Care ${ }^{24}$ for patients with neuropathic cancer pain that is only partially responsive to opioid analgesia. However, the review concluded that adjuvant antidepressants and antiepileptics were unlikely to reduce pain of intensity greater than 1 out of 10 on a numerical rating scale but were likely to increase the frequency of adverse events. ${ }^{33} \mathrm{~A}$ recent review by Kane et al included seven RCTs and a meta-analysis of four RCTs comparing opioids in combination with either gabapentin or pregabalin with opioid monotherapy for cancer pain. There was no significant difference in pain relief between the groups $(\mathrm{SMD}=0.16 ; 95 \% \mathrm{CI}=-0.19$ to $0.51) .^{34}$

Bisphosphonates and denosumab are wellestablished therapies to reduce the frequency and severity of skeletal-related events in patients with bone metastasis. A recent systematic review reported that 22 of 28 placebo-controlled trials (79\%) found no analgesic benefit of bisphosphonates, and none of the investigated denosumab studies found the drug to be associated with direct pain relief. ${ }^{35}$

\section{Evidence-based management of breathlessness}

Breathlessness has been described as an invisible form of suffering. Dyspnoea is an important factor that predicts will to live in terminally ill patients while approaching death. Assessment of the underlying causes and impact of breathlessness is of paramount importance. Addressing cancer- or noncancer-related breathlessness follows a tripartite approach that includes disease management, nonpharmacological management, and pharmacological management.

Non-pharmacological management of breathlessness consists of single-component and complex interventions. Strong evidence indicates that neuroelectric muscle stimulation and chest wall vibration can relieve breathlessness, and there is moderately strong evidence supporting the use of walking aids and breathing training. ${ }^{36}$ An RCT study indicated that airflow delivered to the face by a handheld fan was an effective and simple means to alleviate breathlessness. ${ }^{37}$ To investigate complex interventions, Farquhar et $\mathrm{al}^{38}$ reported an RCT involving 67 patients with cancer who received either a home-based multidisciplinary non-pharmacological Breathlessness Intervention Service (BIS) or usual care. The results showed that BIS reduced patient distress due to breathlessness $(-1.29 ; 95 \% \mathrm{CI}=-2.57$ to $-0.005 ; \mathrm{P}=0.049)$, and was associated with a $66 \%$ likelihood of better outcomes in terms of reduced distress due to breathlessness at lower health/social care costs than standard care. ${ }^{38}$ Higginson et $\mathrm{a}^{39}$ reported an RCT involving 105 patients with mixed advanced disease who received either usual care or Breathlessness Support Service (BSS), which is an out-patient and home-based multiprofessional integrated service that combines respiratory therapy, physiotherapy, occupational therapy, and palliative care. The results showed that BSS improved mastery (mean difference: 0.58 ; $95 \%$ $\mathrm{CI}=0.01-1.15, \mathrm{P}=0.048$; effect size: 0.44 ) compared with usual care, and the BSS group had improved 
survival at 6 months compared with the control group. ${ }^{39}$ In Hong Kong, a multidisciplinary "SOB program" was launched in a cancer palliative care service, leading to improvement in breathlessness scores. ${ }^{40}$

Regarding the use of supplemental oxygen, dyspnoea in terminally ill patients is not significantly correlated with the degree of hypoxaemia. ${ }^{41}$ For non-hypoxaemic, breathless patients with cancer and mixed diagnosis, meta-analysis ${ }^{42}$ and an $\mathrm{RCT}^{43}$ did not show that supplemental palliative oxygen was superior to air; thus, there is no evidence to support its routine use. The largest RCT to date of long-term home oxygen therapy for patients with chronic heart failure was reported by Clark et al. ${ }^{44}$ As only $11 \%$ of patients reported that they used the oxygen for the full 15 hours daily, the trial was stopped early. There was no evidence that home oxygen improved patients' QOL, symptoms, or any other measurement of severity of heart failure, and there was only a non-significant small improvement in survival with oxygen. ${ }^{44}$

The primary pharmacological treatment of breathlessness is the use of systemic opioids. A Cochrane review on opioids for palliation of refractory breathlessness recruited 26 studies of patients with advanced disease and terminal illness. ${ }^{45}$ The meta-analysis demonstrated a small effect of treatment on breathlessness (change from baseline in 7 studies: $\mathrm{SMD}=-0.09,95 \% \mathrm{CI}=-0.36$ to $0.19 ; \mathrm{P}=0.54$; post-treatment score in 11 studies: $\mathrm{SMD}=-0.28,95 \% \mathrm{CI}=-0.50$ to $-0.05 ; \mathrm{P}=0.02) .{ }^{45}$ The authors concluded that there is low-quality evidence illustrating benefits of oral or parenteral opioids to palliate breathlessness. ${ }^{45}$ However, this review has been challenged for its inappropriate method of statistical analysis (ie, using a fixed effect model for crossover designs). ${ }^{46}$ When this review's data were re-analysed using a random effects model that accounted for crossover data, opioids decreased breathlessness $(\mathrm{SMD}=-0.32 ; 95 \% \mathrm{CI}=-0.47$ to -0.18; $\mathrm{P}<0.001)$ compared with placebo, consistent with the findings of earlier studies. ${ }^{46}$ Moreover, a recent systematic review on COPD showed similar positive effects of opioids on breathlessness. ${ }^{47}$ The results showed that breathlessness was reduced by systemic opioids $(\mathrm{SMD}=-0.34,95 \% \mathrm{CI}=-0.58$ to -0.10 , moderate-quality evidence) and less consistently by nebulised opioids (SMD $=-0.39,95 \%$ $\mathrm{CI}=-0.07$ to 0.71 , low-quality evidence), and opioids did not affect exercise capacity. ${ }^{47}$

Regarding the use of benzodiazepines for relief of breathlessness in advanced diseases, a 2016 Cochrane review concluded that there is no evidence for or against benzodiazepines' effectiveness for relief of breathlessness in people with advanced cancer and COPD. Benzodiazepines may be considered as a second- or third-line treatment when opioids and non-pharmacological measures have failed to control breathlessness. ${ }^{48}$

\section{Addressing psychospiritual suffering}

Psychospiritual suffering can present as mood disturbances expressed verbally or through body language or behaviour, wishes to hasten death, or suboptimal pain control. ${ }^{49}$ Suffering can be perceived as an intrapersonal process consisting of an irrevocable past, unbearable present, and incomprehensible future with the source of suffering embedded within loss that threatens the sufferer's sense of self. ${ }^{50}$ It involves common elements such as loss of meaning, hope, and relationships and other associated losses. ${ }^{49}$ A systematic review showed that meaning in life and sense of coherence were significantly negatively associated with distress in patients with cancer. ${ }^{51}$ The challenge of diagnosing psycho-spiritual distress for patients with lifelimiting illness will be differentiation between normal grief, adjustment disorders, anxiety, depression, and demoralisation syndrome. Grief should be distinguished from depression. ${ }^{52}$ Demoralisation presents symptoms of hopelessness and helplessness caused by a loss of purpose and meaning in life, with loss of anticipatory pleasure rather than loss of pleasure in the present moment and general anhedonia, as in depresson. ${ }^{53}$ A systematic review showed that demoralisation syndrome is clinically significant in $13 \%$ to $18 \%$ of patients with progressive disease or cancer ${ }^{53}$ and that up to $25 \%$ of patients with high demoralisation do not have clinical depression..$^{53}$

Various modalities of psychotherapeutic interventions $^{54}$ and antidepressants have been shown to be efficacious for depression in palliative care. ${ }^{55}$ An RCT investigating Individual MeaningCentered Psychotherapy ${ }^{56}$ and Group MeaningCentered Psychotherapy ${ }^{57}$ in patients with advanced cancer demonstrated significantly greater improvement of spiritual well-being, QOL, and symptom burden compared with the control group. An RCT investigating a meaning of life intervention in Hong Kong showed significant improvements in the existential distress subscale, the total score, and the single-item global QOL scale of the QOLC-E. ${ }^{58}$ Moreover, studies of dignity and EOL care have shown a strong association between undermining of dignity and depression, anxiety, desire for death, hopelessness, the feeling of being a burden on others, and overall poorer QOL. ${ }^{59}$ On the basis of Chochinov's empirically based dignity model, patients were offered the opportunity to address the issues that mattered most to them as death drew near to decrease suffering, enhance QOL, and provide a sense of meaning and dignity. ${ }^{60}$ Two Dignity Therapy RCTs have been conducted on patients with high levels of baseline psychological distress. One showed 
statistically significant decreases in patients' anxiety and depression scores measured at 4, 15, and 30 days compared with baseline scores. The other RCT comparing measurements pre-post-Dignity Therapy showed a statistically significant decrease in anxiety scores but not depression. ${ }^{60}$

\section{Palliative and end-of-life care}

There is no unified international definition of the term EOL, and it may have different meanings in different places. In the United Kingdom and Australia, EOL care includes people who are likely to die within 12 months and people whose death is imminent, either from advanced, progressive, incurable conditions or life-threatening acute conditions. It also covers support for their families and caregivers and care provided by health and social care staff in all settings. ${ }^{61}$ Care at the EOL is thus an integral part of palliative care. There is no standardised definition of EOL In Hong Kong, so the term should be defined whenever it is used. No matter which definition is adopted, a person's choice should determine the contents of person-centred care. A survey on "What choices are important to me at the EOL and after my death?" performed in the United Kingdom highlighted the following seven key themes ${ }^{62}$ :

- I want to be cared for and die in a place of my choice

- I want involvement in and control over decisions about my care

- I want the right people to know my wishes at the right time

- I want access to high-quality care given by welltrained staff

- I want access to the right services when I need them

- I want support for my physical, emotional, social, and spiritual needs

- I want the people who are important to me to be supported and involved in my care

A survey on EOL care options in the community

in Hong Kong was conducted in 2011. The results of 1015 completed questionnaires showed that about $90 \%$ of respondents were willing to discuss EOL issues with family members and health care professionals, ${ }^{63}$ and over $30 \%$ of them had actually discussed these issues with family and health care professionals. The five most important attributes of a "good death" were: (1) no acute suffering at the moment of death (89.3\%), (2) difficult symptoms under control (83.6\%), (3) recognising one's disease and prognosis $(82.6 \%)$, (4) not being a burden to family members $(81.0 \%)$, and (5) feeling satisfied with one's life $(80.1 \%){ }^{63}$

Advance care planning is critical for the achievement of patients' EOL goals. Advance care planning enables individuals to define goals and preferences regarding future medical treatment and care when a person is mentally competent, to discuss these goals and preferences with family and health care providers, and to record and review these preferences if appropriate. ${ }^{64}$ A systematic review and meta-analysis showed that advance care planning interventions increase the frequency of completion of advance directives $(\mathrm{OR}=3.26$, 95\% $\mathrm{CI}=2.00-5.32 ; \mathrm{P}<0.001)$, discussions about advance care planning $(\mathrm{OR}=2.82,95 \% \mathrm{CI}=2.09-3.79$; $\mathrm{P}<0.001)$, and concordance between preferences for care and delivered care $(\mathrm{OR}=4.66,95 \% \mathrm{CI}=1.20$ 18.08; $\mathrm{P}=0.03) .{ }^{65}$ In Hong Kong, advance directives were promoted under the existing common law framework instead of by legislation. ${ }^{66}$ The Hospital Authority of Hong Kong issued the Guidance for $H A$ Clinicians on Advance Directives in Adults in 2010 and revised it in $2014 .{ }^{66} \mathrm{With}$ an increasing number of patients with advanced irreversible illnesses staying at home or in residential care homes, the Hospital Authority updated and extended the Guidelines on Do-Not-Attempt Cardiopulmonary Resuscitation to seriously ill non-hospitalised patients (2014/2016). ${ }^{66}$ A population-based telephone survey of 1067 adults in Hong Kong showed $85.7 \%$ of participants had not heard of advance directives, but that $60.9 \%$ would prefer to make their own advance directives if legislation facilitated it. ${ }^{67}$ In terms of lifesustaining treatments, $87.6 \%$ preferred to receive appropriate palliative care rather than prolong life if diagnosed with a terminal illness, whereas $31.2 \%$ of the participants would choose to die at home. ${ }^{67}$ However, a survey performed among palliative patients revealed that only $13.8 \%$ wished to die at home. ${ }^{68}$ Despite the large amount of work needed to align the legal and logistics issues, care at the EOL for older people in residential care homes has been initiated through collaboration between geriatric outreach teams and palliative care teams. ${ }^{69}$

\section{Conclusion}

There is a great need for palliative care both globally and locally in the current era of medicine. The paradigm shift in medicine generated by palliative care alleviates patient suffering and is supported by both science and art.

\section{Author contributions}

The author made substantial contributions to the concept or design, acquisition of data, analysis or interpretation of data, drafting of the article, and critical revision for important intellectual content.

\section{Funding/support}

This research received no specific grant from any funding agency in the public, commercial, or not-for-profit sectors. 


\section{Declaration}

The author has disclosed no conflicts of interest. The author had full access to the data, contributed to the study, approved the final version for publication, and takes responsibility for its accuracy and integrity.

\section{References}

1. Cardona-Morrell M, Kim J, Turner RM, Anstey M, Mitchell IA, Hillman K. Non-beneficial treatments in hospital at the end of life: a systematic review on extent of the problem. Int J Qual Health Care 2016;28:456-69.

2. Lown B. The commodification of health care. Physicians for a national health program. 2007 Newsletter. Available from: http://www.pnhp.org/publications/the_commodification of_health_care.php?page=all. Accessed 14 Mar 2018.

3. Chan KS, Tse DM. Palliative medicine. In: Yu R, editor. Sapientia et Humanitas: A History of Medicine in Hong Kong. Hong Kong: Hong Kong Academy of Medicine Press; 2011: 177-80.

4. Worldwide Palliative Care Alliance and World Health Organization. Global atlas of palliative care at the end of life. Jan 2014. Available from: http://www.who.int/nmh/ Global_Atlas_of_Palliative_Care.pdf. Accessed 14 Mar 2018.

5. Gómez-Batiste X, Connor S, editors. Building integrated palliative care programs and services. May 2017. Available from: http://kehpca.org/wp-content/uploads/ Go\%CC\%81 mez-Batiste-X-Connor-S-Eds.-BuildingIntegrated-Palliative-Care-Programs-and-Services.2017-b.pdf. Accessed 14 Mar 2018.

6. Sixty-seventh World Health Assembly. Strengthening of palliative care as a component of comprehensive care throughout the life course (Agenda item 15.5). 24 May 2014. Available from: http://apps.who.int/gb/ebwha/pdf_ files/WHA67/A67_R19-en.pdf. Accessed 14 Mar 2018.

7. Hospital Authority, Hong Kong SAR Government. Strategic service framework for palliative care. 2017. Available from: http://www.ha.org.hk/haho/ho/ap/PCSSF_1.pdf. Accessed 14 Mar 2018.

8. Centre to advance palliative care. Growth of palliative care in US hospitals 2016 snapshot. 2000-2015. Available from: https://registry.capc.org/wp-content/uploads/2017/02/ Growth-of-Palliative-Care-in-U.S.-Hospitals-2016Snapshot.pdf. Accessed 14 Mar 2018.

9. Kavalieratos D, Corbelli J, Zhang D, et al. Association between palliative care and patient and caregiver outcomes: a systematic review and meta-analysis. JAMA 2016;316:2104-14.

10. Haun MW, Estel S, Rücker G, et al. Early palliative care for adults with advanced cancer. Cochrane Database Syst Rev 2017;(6):CD011129.

11. Gomes B, Calanzani N, Curiale V, McCrone P, Higginson IJ. Effectiveness and cost-effectiveness of home palliative care services for adults with advanced illness and their caregivers. Cochrane Database Syst Rev 2013;(6):CD007760.

12. May P, Normand C, Morrison RS. Economic impact of hospital inpatient palliative care consultation: review of current evidence and directions for future research. J Palliat Med 2014;17:1054-63.

13. Lo RS, Woo J, Zhoc KC, et al. Cross-cultural validation of the McGill Quality of Life questionnaire in Hong Kong Chinese. Palliat Med 2001;15:387-97.
14. Pang SM, Chan KS, Chung BP, et al. Assessing quality of life of patients with chronic obstructive pulmonary disease in the end of life. J Palliat Care 2005;21:180-7.

15. Tse DM, Chan KS, Lam WM, Leu K, Lam PT. The impact of palliative care on cancer deaths in Hong Kong: a retrospective study of 494 cancer deaths. Palliat Med 2007;21:425-33.

16. Wong FK, Ng AY, Lee PH, et al. Effects of a transitional palliative care model on patients with end-stage heart failure: a randomised controlled trial. Heart 2016;102:11008.

17. Maddocks M, Lovell N, Booth S, Man WD, Higginson IJ. Palliative care and management of troublesome symptoms for people with chronic obstructive pulmonary disease. Lancet 2017;390:988-1002.

18. Diop MS, Rudolph JL, Zimmerman KM, Richter MA, Skarf LM. Palliative care interventions for patients with heart failure: a systematic review and meta-analysis. J Palliat Med 2017;20:84-92.

19. Yong DS, Kwok AO, Wong DM, Suen MH, Chen WT, Tse DM. Symptom burden and quality of life in end-stage renal disease: a study of 179 patients on dialysis and palliative care. Palliat Med 2009;23:111-9.

20. Knaul FM, Farmer PE, Krakauer EL, et al. Alleviating the access abyss in palliative care and pain relief-an imperative of universal health coverage: the Lancet Commission report. Lancet 2018;391:1391-454.

21. Cassell EJ. Diagnosing suffering: a perspective. Ann Intern Med 1999;131:531-4.

22. Currow DC, Allingham S, Yates P, Johnson C, Clark K, Eagar K. Improving national hospice/palliative care service symptom outcomes systematically through point-of-care data collection, structured feedback and benchmarking. Support Care Cancer 2015;23:307-15.

23. National Clinical Effectiveness Committee. Pharmacological management of cancer pain in adults, National Clinical Guideline No. 9. Ireland, 2015. Available from: http://health.gov.ie/wp-content/uploads/2015/11/ Pharma-Mgmt-Cancer-Pain_web.pdf. Accessed 14 Mar 2018.

24. Caraceni A, Hanks G, Kaasa S, et al. Use of opioid analgesics in the treatment of cancer pain: evidencebased recommendations from the EAPC. Lancet Oncol 2012;13:e58-68.

25. Nabal M, Librada S, Redondo MJ, Pigni A, Brunelli C, Caraceni A. The role of paracetamol and nonsteroidal antiinflammatory drugs in addition to WHO Step III opioids in the control of pain in advanced cancer. A systematic review of the literature. Palliat Med 2012;26:305-12.

26. Wiffen PJ, Derry S, Moore RA, et al. Oral paracetamol (acetaminophen) for cancer pain. Cochrane Database Syst Rev 2017;(7):CD012637.

27. Derry S, Wiffen PJ, Moore RA, et al. Oral nonsteroidal anti-inflammatory drugs (NSAIDs) for cancer pain in adults. Cochrane Database Syst Rev 2017;(7):CD012638.

28. Straube C, Derry S, Jackson KC, et al. Codeine, alone and with paracetamol (acetaminophen), for cancer pain. Cochrane Database Syst Rev 2014;(9):CD006601.

29. Wiffen PJ, Derry S, Moore RA. Tramadol with or without paracetamol (acetaminophen) for cancer pain. Cochrane Database Syst Rev 2017;(5):CD012508.

30. Caraceni A, Pigni A, Brunelli C. Is oral morphine still the first choice opioid for moderate to severe cancer pain? A 
systematic review within the European Palliative Care Research Collaborative guidelines project. Palliat Med 2011;25:402-9.

31. Schmidt-Hansen M, Bennett MI, Arnold S, Bromham N, Hilgart JS. Oxycodone for cancer-related pain. Cochrane Database Syst Rev 2017;(8):CD003870.

32. Bell GC, Donovan KA, McLeod HL. Clinical implication of opioid pharmacogenomics in patients with cancer. Cancer Control 2015;22:426-32.

33. Bennett MI. Effectiveness of antiepileptic or antidepressant drugs when added to opioids for cancer pain: systematic review. Palliat Med 2011;25:553-9.

34. Kane CM, Mulvey MR, Wright S, Craigs C, Wright JM, Bennett MI. Opioids combined with anti-depressants or antiepileptic drugs for cancer pain: systematic review and meta-analysis. Palliat Med 2018;32:276-286.

35. Porta-Sales J, Garzón-Rodríguez C, Llorens-Torromé S, Brunelli C, Pigni A, Caraceni A. Evidences on the analgesic role of bisphosphonates and denosumab in the treatment of pain due to bone metastases: a systematic review within the European Association for Palliative Care guidelines project. Palliat Med 2017;31:5-25.

36. Bausewein C, Booth S, Gysels M, Higginson I. Nonpharmacological interventions for breathlessness in advanced stages of malignant and non-malignant diseases. Cochrane Database of Syst Rev 2008;(2):CD005623.

37. Galbraith S, Fagan P, Perkins P, Lynch A, Booth S. Does the use of a handheld fan improve chronic dyspnea? A randomized, controlled, crossover trial. J Pain Symptom Manage 2010;39:831-8.

38. Farquhar MC, Prevost AT, McCrone P, et al. Is specialist breathlessness service more effective and cost-effective for patients with advanced cancer and their carers than standard care? Findings of a mixed-method randomized controlled trial. BMC Med 2014;12:194.

39. Higginson IJ, Bausewein C, Reilly CC, et al. An integrated palliative and respiratory care service for patients with advanced disease and refractory breathlessness: a randomised controlled trial. Lancet Respir Med 2014;2:979-87.

40. Chan WL, Ng CW, Lee C, et al. Effective management of breathlessness in advanced cancer patients with a programbased, multidisciplinary approach: The "SOB program" in Hong Kong. J Pain Symptom Manage 2016;51:623-7.e2.

41. Bruera E, Schmitz B, Pither J, Neumann CM, Hanson J. The frequency and correlates of dyspnea in patients with advanced cancer. J Pain Symptom Manage 2000;19:357-62.

42. Uronis HE, Ekström MP, Currow DC, McCrory DC, Samsa GP, Abernethy AP. Oxygen for relief of dyspnoea in people with chronic obstructive pulmonary disease who would not qualify for home oxygen: a systematic review and meta-analysis. Thorax 2015;70:492-4.

43. Abernethy AP, McDonald CF, Frith PA, et al. Effect of palliative oxygen versus room air in relief of breathlessness in patients with refractory dyspnoea: a double-blind, randomised controlled trial. Lancet 2010;376:784-93.

44. Clark AL, Johnson M, Fairhurst C, et al. Does home oxygen therapy (HOT) in addition to standardcare reduce disease severity and improve symptoms in people with chronic heart failure? A randomised trial of home oxygen therapy for patients with chronic heart failure. Health Technol Assess 2015;19:1-120.

45. Barnes H, McDonald J, Smallwood N, Manser R. Opioids for the palliation of refractory breathlessness in adults with advanced disease and terminal illness. Cochrane Database Syst Rev 2016;(3):CD011008.

46. Ekström M, Bajwah S, Bland JM, Currow DC, Hussain J, Johnson MJ. One evidence base; three stories: do opioids relieve chronic breathlessness? Thorax 2018;73:88-90.

47. Ekström M, Nilsson F, Abernethy AA, Currow DC. Effects of opioids on breathlessness and exercise capacity in chronic obstructive pulmonary disease. A systematic review. Ann Am Thorac Soc 2015;12:1079-92.

48. Simon ST, Higginson IJ, Booth S, Harding R, Weingärtner $\mathrm{V}$, Bausewein C. Benzodiazepines for the relief of breathlessness in advanced malignant and nonmalignant diseases in adults. Cochrane Database Syst Rev 2016;(10):CD007354.

49. Cancer Australia, Australian Government. Clinical guidance for responding to suffering in adults with cancer. Jun 2014. Available from: https://canceraustralia.gov.au/ publications-and-resources/clinical-practice-guidelines/ clinical-guidance-responding-suffering-adults-cancer. Accessed 14 Mar 2018.

50. Sacks JL. Suffering at end of life: a systematic review of the literature. J Hosp Palliat Nurs 2013:15;286-97.

51. Winger JG, Adams RN, Mosher CE. Relations of meaning in life and sense of coherence to distress in cancer patients: a meta-analysis. Psychooncology 2016;25:2-10.

52. Block SD. Psychological issues in end-of-life care. J Palliat Med 2006;9:751-72.

53. Robinson S, Kissane DW, Brooker J, Burney S. A systematic review of the demoralization syndrome in individuals with progressive disease and cancer: a decade of research. J Pain Symptom Manage 2015;49:595-610.

54. Kissane DW, Levin T, Hales S, Lo C, Rodin G. Psychotherapy for depression in cancer and palliative care. In: Kissane DW, Maj M, Sartorius N, editors. Depression and Cancer. Chichester: Wiley-Blackwell; 2011: 177-206.

55. Rayner L, Price A, Evans A, Valsraj K, Hotopf M, Higginson IJ. Antidepressants for the treatment of depression in palliative care: systematic review and meta-analysis. Palliat Med 2011;25:36-51.

56. Breitbart W, Rosenfeld B, Pessin H, Applebaum A, Kulikowski J, Lichtenthal WG. Meaning-centered group psychotherapy: an effective intervention for improving psychological well-being in patients with advanced cancer. J Clin Oncol 2015;33:749-54.

57. Breitbart W, Poppito S, Rosenfeld B, et al. Pilot randomized controlled trial of individual meaning-centered psychotherapy for patients with advanced cancer. J Clin Oncol 2012;30:1304-9.

58. Mok E, Lau KP, Lai T, Ching S. The meaning of life intervention for patients with advance-stage cancer: development and pilot study. Oncol Nurs Forum 2012;39:E480-8.

59. Chochinov HM, Hack T, Hassard T, Kristjanson LJ, MsClement S, Harlos M. Dignity in the terminally ill: a cross-sectional, cohort study. Lancet 2002;360:2026-30.

60. Martínez M, Arantzamendi M, Belar A, et al. 'Dignity therapy', a promising intervention in palliative care: a comprehensive systematic literature review. Palliat Med 2017;31:492-509.

61. Australian Commission on Safety and Quality in Health Care. National consensus statement: essential elements for safe and high quality end-of-life care. Sydney: ACSQHC; 
2015.

62. The Choice in End of Life Care Programme Board, Department of Health and Social Care. United Kingdom. What's important to me: a review of choice in end of life care. Feb 2015. Available from: https://www.gov.uk/ government/uploads/system/uploads/attachment_data/ file/407244/CHOICE_REVIEW_FINAL_for_web.pdf. Accessed 14 Mar 2018.

63. Society for the Promotion of Hospice Care. Survey on endof-life care opinions in Hong Kong. 2011. Available from: http://hospicecare.cloudhost8.com/wp-content/uploads/2 017/09/20111003acpsurvey-whd11.pdf. Accessed 14 Mar 2018.

64. Rietjens JA, Sudore RL, Connolly M, et al. Definition and recommendations for advance care planning: an international consensus supported by the European Association for Palliative Care. Lancet Oncol 2017;18:e54351.
65. Houben CH, Spruit MA, Groenen MT, Wouters EF, Janssen DJ. Efficacy of advance care planning: a systematic review and meta-analysis. J Am Med Dir Assoc 2014;15:477-89.

66. Tse CY. Reflections on the development of advance directives in Hong Kong. Asian Bioeth Rev 2016;8:211-23.

67. Chung RY, Wong EL, Kiang N, et al. Knowledge, attitudes, and preference of advance decisions, end-of-life care, and place of care and death in Hong Kong. A population-based telephone survey of 1067 adults. J Am Med Dir Assoc 2017;18:367.e19-27.

68. Woo RK, Kwok AO, Tse DM. Preferred place of care and death among the terminally ill: Asian perspectives and implications for Hong Kong. In: Fong B, Ng A, Yuen P, editors. Sustainable Health and Long-term Care Solutions for an Aging Population. Hershey: IGI Global; 2018: 277-93.

69. Luk JK. End-of-life services for older people in residential care homes in Hong Kong. Hong Kong Med J 2018;24:63-7. 